\title{
Transmission dynamics of the amphibian ranavirus Ambystoma tigrinum virus
}

\author{
J. L. Brunner ${ }^{1,2, *}$, D. M. Schock ${ }^{1}$, J. P. Collins ${ }^{1}$ \\ ${ }^{1}$ School of Life Sciences, Arizona State University, Tempe, Arizona 85287-4501, USA \\ ${ }^{2}$ Present address: Institute of Ecosystem Studies, PO Box AB, Millbrook, New York 12545, USA
}

\begin{abstract}
Transmission is central to pathogen fitness and strongly influences the impact of pathogens on host populations. Particularly important to transmission dynamics is the distinction between direct transmission requiring close physical contact (e.g. bumping, fighting, or coughing) and indirect transmission from environmental sources such as contaminated substrates. We present data from 4 experiments addressing the form, routes, and timing of transmission of Ambystoma tigrinum virus (ATV) among tiger salamanders Ambystoma tigrinum nebulosum. Our data suggest that ATV is efficiently transmitted by direct interactions between live animals (bumping, biting and cannibalism) as well as by necrophagy and indirectly via water and fomites. Determining which form of transmission is most important in nature is essential for understanding transmission at the population level. Our experiments also revealed an important temporal aspect of infectiousness: larval salamanders become infectious soon after exposure to ATV and their propensity to infect others increases with time. These results begin to clarify the mechanisms and dynamics of ATV transmission and lead to key questions that need to be addressed in future research.
\end{abstract}

KEY WORDS: Ambystoma tigrinum virus · ATV • Tiger salamander · Transmission • Ranavirus • Iridoviridae

Resale or republication not permitted without written consent of the publisher

\section{INTRODUCTION}

Transmission is a central feature of pathogen fitness (Anderson \& May 1982, Levin 1996, Day 2001) and influences how a pathogen affects its host population. The form and magnitude of transmission rates help determine whether a pathogen establishes itself in a host population, whether an epidemic ensues, and the proportion of a population that becomes infected (Anderson \& May 1991, Daley \& Gani 1999, Hudson et al. 2002). A pathogen transmitted via close contacts bumping, fighting, or coughing, for exampledepends upon sufficient numbers or densities of hosts for continued transmission and persistence. When hosts become rare, transmission ebbs and the pathogen 'fades out' (Dobson \& Hudson 1986, Lyles \& Dobson 1993). However, if the infection is acquired from the environment (e.g. by feeding on contaminated substrates) transmission continues even as host numbers or densities decline. Under these conditions the pathogen could drive the host extinct (Dobson \& May 1986, Dye et al. 1995, de Castro \& Bolker 2005). Any effort to predict or mitigate the causes and consequences of epidemics requires an understanding of transmission. Here we examine the transmission of the emerging Ambystoma tigrinum virus (ATV), a lethal ranavirus affecting the tiger salamander Ambystoma tigrinum (Jancovich et al. 1997).

Ranaviruses are a group of double-stranded DNA viruses in the family Iridoviridae that infect fish, reptiles, and amphibians (for recent reviews, see Chinchar 2002, Williams et al. 2005). The first amphibian ranaviruses isolated were not generally lethal, except to the larvae of certain amphibian species, and there was little to suggest they caused mass mortality in the wild (Chinchar 2002). The identification of ATV as the cause of large die-offs of tiger salamanders across North America (Jancovich et al. 1997, Bollinger et al. 
1999, Docherty et al. 2003) and of Frog Virus 3 as the causative agent of several wood frog Rana sylvatica and northern leopard frog $R$. pipiens die-offs (Green et al. 2002, Greer et al. 2005) suggested that these viruses play larger roles in the population dynamics of their hosts than previously thought. The ATV-tiger salamander system is becoming an excellent model for studying emerging infectious diseases of wildlife (Collins et al. 2004). The key to developing this model system is a better understanding of ATV transmission dynamics.

Jancovich et al. (1997) demonstrated ATV transmission among tiger salamanders in water that previously housed lethally infected conspecifics, even after passage through a $0.45 \mu \mathrm{m}$ filter to remove fomites. They also transmitted ATV by feeding naïve larvae pieces of body wall from infected larvae. Parris et al. (2005) infected naïve tiger salamander larvae with ATV using infected larvae in floating mesh bags in a mesocosm. Successful transmission of ATV depended on dose in experimental water-bath exposures (Brunner et al. 2005). These results suggested that regardless of whether the source was environmental or another host, transmission occurred when hosts encountered sufficient quantities of virus. However, several questions are outstanding. For example, does transmission vary depending on the type of contact? Is a bump sufficient for transmission or is cannibalism or necrophagy required? How readily is the virus transmitted from environmental sources such as pond water or sediment? How soon after exposure does a host start shedding sufficient virus to infect others? Does the ability to infect others vary throughout an infection? We summarize 4 experiments that address each of these questions under ecologically realistic conditions. The answers to each question affect many particulars in an epidemiological model of this and other related ranaviral systems that include species of fish, turtles, frogs, and salamanders.

\section{MATERIALS AND METHODS}

Source of animals and virus. All experiments used Ambystoma tigrinum nebulosum larvae at least 3 mo old from our breeding colony. These lines of A. t. nebulosum were originally derived from the White Mountains in eastern Arizona. Screening of the breeding colony animals and the control animals used in these and other experiments has produced no evidence of ranavirus infection. We housed larvae individually in plastic containers with tight-fitting lids (Ziploc ${ }^{\mathrm{TM}}$ box, S.C. Johnson) and air holes. Experiments were conducted in a laboratory maintained at 20 to $22^{\circ} \mathrm{C}$ with a $12 \mathrm{~h}$ light-12 h dark cycle. Each larva was fed 2 mealworms twice per week and transferred to a new container with clean water once each week. All animals were cared for in accordance with the Guide for the Care and Use of Laboratory Animals (Institute of Laboratory Animal Resources, National Research Council 1996) and all research was conducted with approval from the Arizona State University Institutional Animal Care and Use Committee (Protocols 99526R and 03-670R).

ATV isolates used in the experiments were derived from tiger salamander carcasses found during die-offs on the Kaibab Plateau in Northern Arizona in 2000 and confirmed as ATV by comparing the sequence of the major capsid protein with published data (Jancovich et al. 2005). We grew the virus in epithelioma papulosum cyprini (EPC) cells (Fijan et al. 1983) under conditions described by Jancovich et al. (1997). Before use, the ATV in EPC cells was frozen and thawed 2 to 3 times to lyse cells and titered using plaque assays. Mockexposed animals were exposed to EPC cells + culture media.

Expt 1: routes of transmission. The objective was to assess the relative efficiency of ranavirus transmission via 4 ecologically realistic routes: direct contact with mucous from infected individuals, cannibalism/ necrophagy, fomites from infected individuals, and fomite-free water that had housed infected individuals.

Eight larvae were infected with ATV via water bath for $2 \mathrm{~d}\left(200 \mathrm{ml}\right.$ of $10^{4}$ plaque forming units [pfu] $\mathrm{ml}^{-1}$ diluted in aged tap water, for a total inoculum of $2 \times 10^{6}$ pfu) in plastic containers and then transferred to containers with clean water. After $8 \mathrm{~d}$ these larvae were euthanized with a sharp blow to the head. We used each ATV-infected animal to create 4 experimental treatments to which 8 naïve larvae were assigned randomly. One replicate of the fomite treatment was accidentally lost.

Direct contact treatment (a): to isolate material that might be transferred by physical contact between animals such as bumping, but short of biting, a clean glass slide was rubbed over the entire surface of each focal animal to collect mucous and/or virions attached to the skin. The slide was then dropped into $400 \mathrm{ml}$ of aged tap water in a clean container and a naïve larva added. We removed the slide when cages were changed $1 \mathrm{wk}$ later.

Necrophagy/cannibalism treatment (b): a piece of a tail $(0.10$ to $0.15 \mathrm{~g})$ was taken from each focal animal and fed to a naïve larva. We enticed each naïve larva to eat the tail clip by rubbing the tail clips in ground up mealworms, the larva's main food. After the naïve larvae ate a tail clip, they were transferred to new containers with clean water to minimize the effects of virions that the tail clips might have shed into the water. 
Filtered water (c) and fomite treatments (d): we filtered the $400 \mathrm{ml}$ of water previously inhabited by each of the 8 focal animals through analytical filter paper (Eaton-Dikeman) and then through $0.8 \mu$ filters (Gelman Sciences) into 8 new containers, and then placed a naïve larva in each. This pore size permits passage of virions (Jancovich et al. 1997) but not larger debris with virus attached, thereby allowing us to test whether free virus is an important source of infection. We placed another 8 naïve larvae in containers with $400 \mathrm{ml}$ of aged tap water and the filters from each focal animal, which contained fomites shed by the focal larvae. The filters were removed when we changed the cages 1 wk later.

All surviving larvae were euthanized with a sharp blow to the head $21 \mathrm{~d}$ after exposure. All animals in all treatments were frozen at $-80^{\circ} \mathrm{C}$ upon death until they were screened for ATV infection using polymerase chain reaction (PCR). To test for potential contamination in the experiment, 8 larvae were mock-exposed to filtered water that had housed 8 naïve larvae. All 8 larvae survived to Day 21 and tested negative for the virus (data not shown).

Expt 2: environmental sources of ranavirus. We wanted to know whether ponds are environmental reservoirs for ATV, particularly whether ATV in the sediments could infect salamander larvae. We also wanted to know whether ATV persists after ponds dry, a common event in many amphibian breeding ponds. We collected pond sediment (mud) from 3 earthen livestock tanks on the Mogollon Rim in Arizona (27 Mile Tank, Tanque Aloma, and Divide Tank) used as breeding ponds by tiger salamanders and other amphibians. Sediment was autoclaved, dried, and homogenized with a mortar and pestle. Of the dried, ground sediment, $15 \mathrm{~g}$ was added to each of 30 plastic containers per pond and rehydrated with $50 \mathrm{ml}$ aged tap water. Twenty containers per pond received a total of $2 \times$ $10^{7}$ pfu of ATV and 10 were uninfected controls with equivalent amounts of uninfected EPC cells + cell culture media added. Ten virus + sediment replicates were allowed to air dry at $20^{\circ} \mathrm{C}$ while the other 10 virus + sediment replicates and $10 \mathrm{EPC}$ + sediment controls were kept at relatively constant volume by keeping the containers loosely covered with lids. Containers that were not covered were dry after $4 \mathrm{~d}$, at which point all containers in all treatments were filled to a volume of $300 \mathrm{ml}$ with aged tap water. In containers that received virus, the resulting virus concentration was $6.67 \times$ $10^{4} \mathrm{pfu} \mathrm{ml}^{-1}$, assuming all of the initial virus inoculum remained active. Once the sediment particles settled ( 15 min), a randomly selected naïve larva was added to each container. These larvae were observed for clinical signs of ATV infection (Jancovich et al. 1997) for $30 \mathrm{~d}$, at which point all remaining animals were eutha- nized with an overdose of MS-222. All animals in all treatments were frozen at $-80^{\circ} \mathrm{C}$ immediately after death until screened for virus with PCR.

Changes in transmission through time: we suspected that a salamander larva might become infectious, or more infectious, after it developed clinical signs of infection associated with virus production and/or shedding such as papules, lesions, and/or stringy white cloacal exudates. These signs generally take 8 to $14 \mathrm{~d}$ to develop, so we hypothesized that the probability of ATV transmission would increase with time and might be a binary function of the focal animal presenting these signs. There might also be behavioral changes during the course of an infection that would change transmission rates. We conducted 2 experiments to determine how time since infection influenced the ability of a focal animal to transmit the infection. In the first of these 2 experiments (Expt 3) we tested transmission from a single physical contact, which isolated transmissibility from actual transmission rates. In the second (Expt 4), we examined how transmission rates might change under more realistic conditions allowing for multiple contacts and behavioral interactions.

Expt 3: infectiousness through time. We intraperitoneally injected 21 focal larvae with 500 pfu of ATV in $200 \mu \mathrm{l}$ of inoculum. At each of 7 time points $(4,5,6,7$, 8,9 , and $13 \mathrm{~d}$ after injection) we haphazardly selected without replacement 3 of the infected focal larvae and 3 naïve larvae. Each naïve larva was exposed to a focal larva by holding (out of water) the 2 animals' ventral surfaces together for $\sim 1 \mathrm{~s}$. This exposure protocol simulated a single, perhaps slightly prolonged, contact between 2 animals that might occur naturally. The animals were then returned to separate plastic containers with $400 \mathrm{ml}$ aged tap water and observed for evidence of ATV infection until death or for 45,46 , or $47 \mathrm{~d}$, at which point they were euthanized with an overdose of MS-222. Each animal was handled with new latex gloves to avoid accidental transmission. Unfortunately, the samples from these larvae were lost before they could be screened for virus infection with PCR, so we report only mortality rates and rates of expression of characteristic lesions of ATV infection (papules and cloacal exudates).

Expt 4: transmission rates through time. We refined our approach to the questions of when an animal becomes infectious and how transmission rates change throughout the course of an infection. Three focal larvae were experimentally infected with ATV via individual $24 \mathrm{~h}$ water baths $\left(400 \mathrm{ml}\right.$ of $10^{4} \mathrm{pfu} \mathrm{ml}^{-1}$ diluted in aged tap water; $4 \times 10^{6}$ pfu total) in plastic containers and then removed to containers with clean water. Two days after initial exposure, and then again every other day for $10 \mathrm{~d}$ (Focal A and B) or $16 \mathrm{~d}$ (Focal C), 
focal larvae were each co-housed for $24 \mathrm{~h}$ with different groups of 10 naïve larvae in a glass aquarium $(90 \mathrm{~cm} \times 45 \mathrm{~cm} \times 44 \mathrm{~cm})$ containing $100 \mathrm{l}$ of aged tap water. Every group of 10 naïve larvae (a total of 5 groups for each of Focal A and B, and 8 groups for Focal C) included animals from each of 5 lab-bred clutches assigned haphazardly into groups to ensure roughly equivalent size distributions. The water was continually circulated through a 9 W UV sterilizer (Coralife, Energy Savers Unlimited) connected to a 51 min $^{-1}$ pump (Eheim) to inactivate free circulating virus. ATV transmission was therefore presumed to occur primarily through direct contact between the focal larva and naïve larvae. After $24 \mathrm{~h}$, the newly exposed larvae were removed from the aquarium and their snout-vent length (SVL, in $\mathrm{mm}$ ) was measured. They were then placed in individual containers and monitored for $10 \mathrm{~d}$ to allow any newly acquired infections to develop. After $10 \mathrm{~d}$ of observation, the surviving larvae were euthanized. All exposed larvae were frozen at $-80^{\circ} \mathrm{C}$ immediately after death until processed for virus screening with PCR. Each animal was removed from the aquarium with a clean, disinfected net and handled with new latex gloves to avoid cross contamination. The aquaria were drained, disinfected with a $10 \%$ bleach solution, rinsed, and allowed to dry between each exposure. The probability of the naïve larvae becoming infected was modeled with a logistic regression. Several alternate models were constructed to determine the influence of the number of days since the focal animal was infected, the identity of the focal larva, the size of the focal larva (SVL), the size of naïve larvae (SVL), and the size of naïve larvae relative to the focal larva (smaller, larger, or the same within $2 \mathrm{~mm}$ SVL). These alternate models were then compared using Akaike's information criterion corrected for sample size (AICc) and AICc weights $\left(\mathrm{w}_{i}\right)$, which provide a measure of the proportion of evidentiary support within the dataset for each model (Burnham \& Anderson 2002).

Virus detection with PCR. Frozen carcasses were thawed on ice and ground in 5 to $10 \mathrm{ml}$ of hypotonic lysis buffer (0.1 M NaCl, 0.05 M Tris-HCl, $\mathrm{pH}$ 8, $0.001 \mathrm{M}$ EDTA) for $90 \mathrm{~s}$ using a Stomacher $^{\circledR} 80$ (Seward). The whole animal was ground and DNA was extracted from a $100 \mu \mathrm{l}$ sample of this slurry using the PUREGENE ${ }^{\circledR}$ protocol (Gentra Systems). To determine the infection status of each sample, we amplified a $\sim 500 \mathrm{bp}$ fragment of the $5^{\prime}$ end of the major capsid protein (MCP) by PCR, using primers \#4 and \#5 described by Mao et al. (1996) for FV3. PCR products were visualized by electrophoresis on $2 \%$ agarose gels using SYBR ${ }^{\circledR}$ Green nucleic acid stain (Molecular Probes) on a Dark Reader transilluminator (Clare Chemical Research). Negative samples were tested twice, then re-extracted and tested for virus twice again.

\section{RESULTS}

\section{Expt 1: routes of transmission}

At least 3 larvae became infected via each route of transmission (Fig. 1). The difference in the number of larvae infected via each route was not significant $\left(\chi^{2}=\right.$ 6.00 , df $=3, p=0.112$ ), presumably because of low sample sizes. There appeared to be differences among the ATV-infected larvae in their ability to infect others-1 ATV-infected animal infected all 4 larvae exposed to it while another infected only 1 - but this variability was not significant $\left(\chi^{2}=9.313\right.$, df $=7, \mathrm{p}=$ $0.231)$. Mortality rates mirrored infection rates: all exposed larvae died before the experiment's end except for 1 larva exposed to a skin scrape, which was infected but survived to the end of the experiment $(21 \mathrm{~d})$

\section{Expt 2: environmental sources of ranavirus}

There was no mortality or infection in any control larva. Similarly, there was no mortality or ATV infection in any larva exposed to virus that had dried in pond substrate. When the virus and pond substrate were kept moist, however, 26 of 30 (86.7\%) larvae

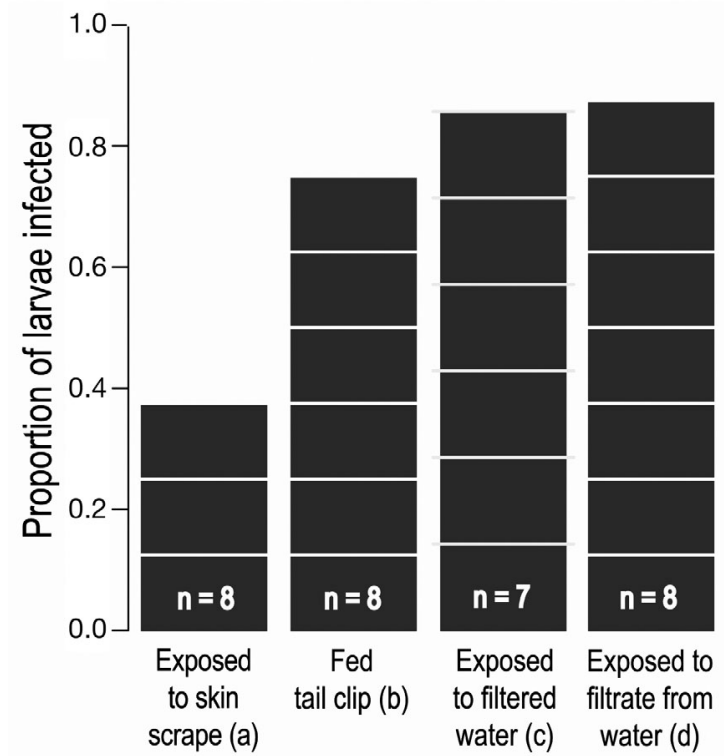

Fig. 1. Ambystoma tigrinum nebulosum. Proportion of larvae infected within $21 \mathrm{~d}$ of exposure in each treatment of Expt 1. White lines divide bars into boxes, each of which represents an individual animal 
Table 1. Expt 2: Ambystoma tigrinum virus (ATV) was added to sterilized pond substrate from each of 3 ponds, placed in plastic containers, and either allowed to dry or kept moist. Aged tap water and a naïve larva were added to each container. Data are number of animals that became infected and died out of 10

\begin{tabular}{|lcc|}
\hline Pond & Moist & Dried \\
\hline Aloma & 10 & 0 \\
Divide & 8 & 0 \\
27 Mile & 8 & 0 \\
\hline
\end{tabular}

became infected and died with little variation among ponds (Table 1). The infection rates from substrates from the 3 ponds were not significantly different $\left(\chi^{2}=\right.$ 2.31, df $=2, p=0.315$ ).

\section{Expt 3: infectiousness through time}

A $1 \mathrm{~s}$ ventral surface-to-ventral surface contact between infected and naïve larvae caused infection in 18 $(85.7 \%)$ of 21 larvae (Table 2 ) and at least 2 of 3 naïve larvae developed signs of ATV infection at each time point. The odds of becoming infected did not change with time from injection of the focal larvae (odds ratio $=$ 1.50, $95 \%$ CI: 0.74 to $3.08, \beta$ (slope) $=0.41 \pm 0.37$, z-test statistic $=1.12, p=0.263)$. However, there was a significant negative relationship between the time since a focal larva was injected with virus and the number of days before evidence of infection was visible in the exposed larvae $(\beta=-0.95 \pm 0.37, t=-2.55, \mathrm{p}=0.022)$. In addition, the mean time until presentation of clinical signs in naïve larvae was less when the focal larva itself had signs of infection (15.3 d for apparently healthy focal larvae versus $9.7 \mathrm{~d}$ for those with signs; Welch's $t=3.56, \mathrm{df}=12.3, \mathrm{p}=0.004)$.

Table 2. Ambystoma tigrinum nebulosum. Expt 3: focal larvae were injected with ATV. To simulate a potentially infectious contact, 3 naïve larvae were held ventral surface to ventral surface for $\sim 1 \mathrm{~s}$ on 7 occasions from 4 to 9 or $13 \mathrm{~d}$ post-injection

\begin{tabular}{|lcccccc|}
\hline \multirow{2}{*}{$\begin{array}{l}\text { Day of } \\
\text { exposure } \\
\text { (post- } \\
\text { injection) }\end{array}$} & $\begin{array}{c}\text { Days until signs } \\
\text { of infection } \\
\text { (mean } \pm \text { SD) }\end{array}$ & $\begin{array}{c}\text { infection when } \\
\text { contacted? }\end{array}$ & & $\begin{array}{c}\text { Signs } \\
\text { Presented signs } \\
\text { of infection } \\
\text { (out of 3) }\end{array}$ & $\begin{array}{c}\text { signs of infection } \\
\text { (mean } \pm \text { SD) }\end{array}$ & \\
\hline 4 & $16.7 \pm 4.0$ & No & 2 & $14.5 \pm 0.7$ & 0 \\
5 & $14.0 \pm 1.7$ & No & 3 & $17.0 \pm 3.5$ & 0 \\
6 & $17.0 \pm 3.6$ & No & 2 & $25.0 \pm 2.8$ & 0 \\
7 & $15.3 \pm 2.1$ & No & 2 & $12.0 \pm 0$ & 0 \\
8 & $14.7 \pm 1.2$ & No & 3 & $12.7 \pm 4.6$ & 1 \\
9 & $13.0 \pm 1.0$ & No & 3 & $12.7 \pm 4.0$ & 2 \\
13 & $13.0 \pm 0$ & Yes & 3 & $9.7 \pm 1.5$ & 1 \\
\hline
\end{tabular}

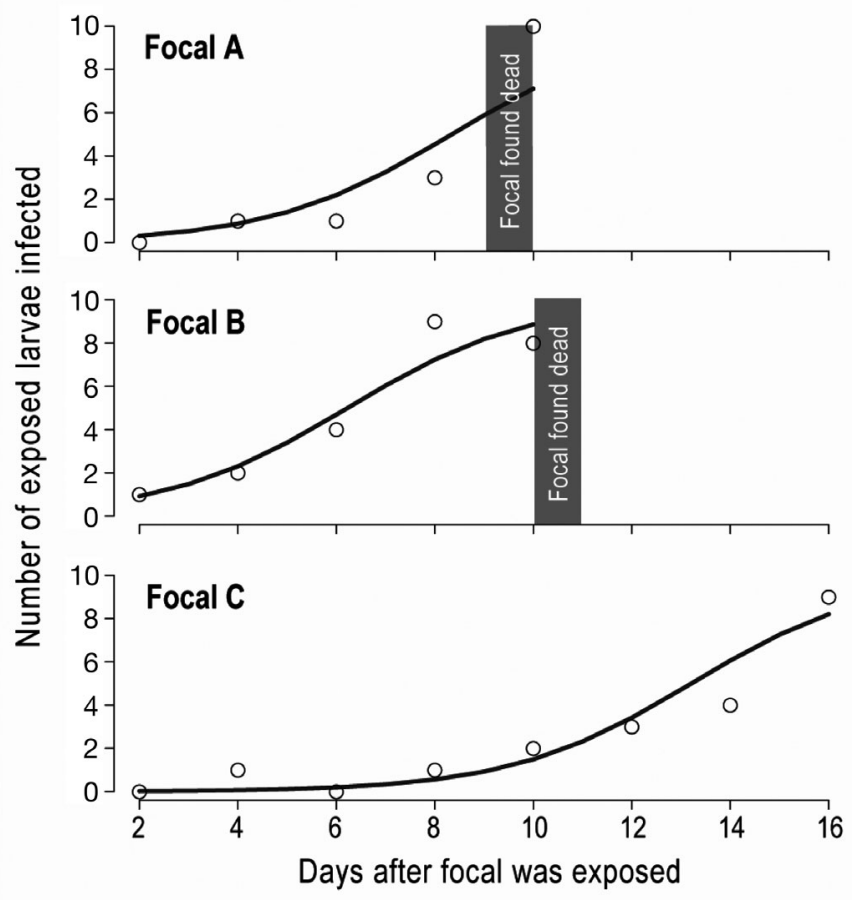

Fig. 2. Ambystoma tigrinum nebulosum. Number of naïve larvae infected by each of the 3 focal larvae in Expt 4 during $24 \mathrm{~h}$ exposures every other day. (0): number infected in each exposure period, solid lines: logistic regression of infection rates on the number of days since the focal larva was exposed and the focal larva identity. Note: Focal A was found dead just before it was placed with its Day 10 exposure group. Focal B was alive before being placed with its Day 10 exposure group, but was found dead the next day when larvae were separated. Focal C did not die until 18 d post-exposure

\section{Expt 4: transmission rates through time}

The 3 focal larvae infected $59(32.8 \%)$ of 180 exposed larvae, averaging 3, 4.8, and 3.3 infected larvae during each exposure period for focal larvae $A, B$, and $\mathrm{C}$, respectively (Fig. 2). Focal A died $10 \mathrm{~d}$ after it was experimentally infected with ATV, before the last group of larvae was introduced into the exposure tank with it, while Focal $B$ was found dead on Day 11 (at the end of the Day 10 exposure period). Focal C survived until Day 18.

The best single-factor logistic regression model, based on AICc values, was the model with the probability of infection increasing with the number of days since the focal larva was infected (Table 3, Model 6). The best model overall included days since the focal larva was infected, the identity of the focal larva, and the SVL of the 
Table 3. Support for alternate logistic regression models of Expt 4. Day: number of days since the Ambystoma tigrinum nebulosum focal larva was infected, Focal ID: identity of the focal larva, SVL: snout-vent length $(\mathrm{mm})$ of the exposed larva, Relative size: categorical variable indicating whether an exposed larva was smaller, larger, or the same size as the focal larva (within $2 \mathrm{~mm}$ ), $k$ : number of parameters in the model, $\triangle$ AICc: difference in Akaike's information criterion, corrected for sample size, between each model and the best overall model, $w_{i}$ : Akaike weight for each model (Burnham \& Anderson 2002)

\begin{tabular}{|lcccc|}
\hline Model & $k$ & AICC & $\Delta$ AICc & $w_{i}$ \\
\hline 1) Day + Focal ID + SVL & 5 & 149.5 & 0 & 0.70 \\
2) Day + Focal ID + Relative size & 6 & 152.7 & 3.1 & 0.15 \\
3) Day x Focal ID & 6 & 153.8 & 4.2 & 0.08 \\
4) Day + Focal ID & 4 & 154.2 & 4.7 & 0.07 \\
5) Day + SVL (focal larva) & 3 & 187.6 & 38.1 & 0 \\
6) Day & 2 & 191.9 & 42.3 & 0 \\
7) Day + Relative size & 4 & 192.7 & 43.2 & 0 \\
8) Day + SVL & 3 & 192.7 & 43.2 & 0 \\
9) Focal ID & 3 & 226.4 & 76.9 & 0 \\
10) SVL & 2 & 226.5 & 76.9 & 0 \\
11) Relative size & 2 & 227.1 & 77.5 & 0 \\
12) SVL (focal larva) & 2 & 227.7 & 78.1 & 0 \\
\hline
\end{tabular}

exposed larva. In this latter model, the odds of a naïve larva becoming infected increased 1.75-fold every day after the focal larva was infected $\left(\beta_{\text {day }}=0.561 \pm 0.089\right.$, $z=6.31, \mathrm{p}<0.001$ ), and increased 2.34-fold with a $10 \mathrm{~mm}$ increase in SVL $\left(\beta_{\mathrm{SVL}}=0.085 \pm 0.034, z=2.47, \mathrm{p}\right.$ $=0.013)$. The identity of the focal animal was also important $\left(\chi^{2}=47.42, \mathrm{df}=2, \mathrm{p}<0.001\right)$. Compared to Focal A, a naïve larva housed with Focal B was 3.24 times more likely to be infected, and a larva housed with Focal $C$ was 22 times less likely to be infected $\left(\beta_{\text {FocalB }}=1.175 \pm 0.536, z=2.19, \mathrm{p}=0.028 ; \beta_{\text {FocalC }}=\right.$ $-3.098 \pm 0.731, z=-4.24, \mathrm{p}<0.001)$.

\section{DISCUSSION}

\section{Form and route of transmission}

ATV is transmitted among tiger salamander larvae via several routes of exposure.

\section{Direct contact}

The direct contact treatment (a) in Expt 1 generated few infections (Fig. 1), but this may have been because larvae did not contact the mucous and scrapings on the glass slide. The high level of infection in Expt 3 suggests that simple physical contact can be an efficient form of transmission (Table 2). The conditions of Expt 4 were less contrived and allowed for more normal bumping and behavioral interactions while minimizing other forms of transmission (e.g. fomites and waterborne transmission). As in Expt 3, transmission frequently occurred. Combined, these results suggest that simple physical contact, such as bumping, is both a common and successful form of ATV transmission.

Normal behavioral interactions among tiger salamander larvae include nipping at the tail, feet, and snouts of other larvae, lunging, and even cannibalism (discussed below). Consuming a small piece of tissue from an infected animal ensured infections in 6 of 8 larvae (Fig. 1), suggesting aggressive interactions are an efficient route of ATV transmission. High population densities and low variability in the size structure of larval populations tend to increase competition and therefore antagonistic interactions among larvae (Maret \& Collins 1994, Brunkow \& Collins 1998). Aggressive behaviors also increase with the size of tiger salamander larvae (Brunkow \& Collins 1998). We cannot address the importance of density or size structure because densities were identical in all of the Expt 4 treatments and the coefficients of variation of SVL of the naïve larvae did not differ among focal larva $\left(F_{2,177}=0.048, \mathrm{p}=0.953\right)$ or with time $\left(F_{1,128}=0.1422\right.$, $\mathrm{p}=0.707)$. Size of the exposed larvae, however, appears to be important. The 2 best logistic regression models generated for Expt 4 included some measure of the size of the exposed animals. In the best modelwhich included days since the focal larva was infected, the identity of the focal larva, and the SVL of the exposed larva-increasing size meant increasing risk of infection: 2.3 times greater risk for every $10 \mathrm{~mm}$ in SVL. Absolute size of the exposed larva was a better predictor of infection than its relative size (compare Model 1, 2 in Table 3).

Cannibalism may also influence virus transmission dynamics in tiger salamander populations, although how, exactly, is unclear. The largest tiger salamander larvae in a population commonly consume smaller conspecifics, sometimes even developing a specialized cannibal morphology (Collins \& Cheek 1983, Collins \& Holomuzki 1984, Maret \& Collins 1994). Cannibals do not appear to avoid consuming diseased animals (Pfennig et al. 1998; infectious agent unknown in their study) and in mesocosm experiments, the expression of the cannibalistic phenotype did not differ between ATV-exposed and unexposed populations (Parris et al. 2005). Infected individuals tend to be more lethargic (Parris et al. 2004), so it is possible that cannibals may remove infected individuals from the population, perhaps even preferentially. If so, cannibalism may result in lower contact rates, and therefore transmission rates, due to removal of infected individuals. In areas with frequent ATV epizootics, the cannibalistic phenotype would likely be selected against, a prediction sup- 
ported by Pfennig et al. (1991), who found a negative correlation between the frequency of epizootic mortality in tiger salamander populations in Arizona and the propensity of animals from these populations to develop into cannibals. The interplay between cannibalism and ranavirus transmission is unclear, but likely important.

Focals A and B from Expt 4 both exhibited evidence of necrophagy. Necrophagy is a common (Jancovich et al. 1997, 2001, Pearman et al. 2004, Harp \& Petranka 2006) but distinct route of transmission, akin to adding an extra infectious period after the animal has died, which should increase transmission rates. Larvae may also seek carcasses to feed upon, in which case transmission would no longer be passive and density dependent, but rather active and therefore frequency dependent. Harp \& Petranka (2006), for instance, found that necrophagy was an important route of ranavirus transmission in the wood frog Rana sylvatica. Moreover, the timing and overall mortality of wood frog-ranavirus epidemics in mesocosms did not change with the density of susceptible hosts, a pattern that is consistent with frequency dependent transmission. Our results also indicate the important role of scavenging on carcasses. For example, Focal A in Expt 4 was most infectious in the last exposure period, when it was dead. It may be necessary to include carcasses as a distinct element of epidemiological models of ranavirus epidemics.

\section{Indirect contact}

Consistent with previous ranavirus studies (Wolf et al. 1969, Jancovich et al. 1997, Pearman \& Garner 2005), we found that ATV was transmitted by exposure to free-floating mucous and other material shed by infected animals (i.e. fomites, Expt 1, Treatment d), and exposure to water free of this shed material (Fig. 1, Treatment c). The virus also remained infectious for $4 \mathrm{~d}$ in sterile sediment that was kept moist (Table 1). We do not know how our experiments compare to whole ponds with normal flora, fauna, and currents, but our experiments would seem to represent worst case scenarios for 2 reasons. First, we spiked the sediments in Expt 2 with more than enough virus to ensure infection: we used $2 \times 10^{7}$ pfu of ATV in approximately $60 \mathrm{ml}$ of wet sediment, knowing that waterbath exposure to $\sim 10^{2}$ virions $\mathrm{ml}^{-1}$, or $2 \times 10^{4}$ virions in total, causes infection in $>95 \%$ of larvae (Brunner et al. 2005). We know of no reports of ranavirus titers in pond sediment or of overall transmission rates from contaminated sediments, but Harp \& Petranka (2006) were able to infect at least some naïve wood frog tadpoles by exposing them to sediment taken from a pond during an active ranavirus epidemic. Interestingly, although tadpoles from most replicates in their experiment tested positive for ranavirus, all remained apparently healthy until metamorphosis, suggesting that these tadpoles were exposed to low doses of ranavirus in the sediment, resulting in sublethal infections.

The second reason our experimental conditions represent an extreme case is that ATV appears to degrade in non-sterile pond water. In a preliminary experiment (J. L. Brunner unpubl. data), ATV titers in pond water dropped by several orders of magnitude in $2 \mathrm{wk}$. Attempts to replicate these results have met with continued technical problems (e.g. bacterial contamination in cell culture assays), but do suggest a wide range of persistence times ( $1 \mathrm{~d}$ to $4 \mathrm{wk}$ ). Water chemistry and temperature can vary dramatically from pond to pond and through time within a pond, which would likely influence the survival of virions.

Epidemiological models demonstrate that the difference between direct and indirect transmission is not trivial. Future experiments must consider 'how close is close' and how far the 'sphere of infectiousness' extends when evaluating the importance of indirect transmission to ranavirus dynamics. As this sphere enlarges to encompass most, or all, of a habitat, host density influences transmission rates less; therefore, transmission is more accurately modeled as coming from the environment. These details are unresolved in the ATV-tiger salamander system.

\section{Vertical transmission}

Lastly, we should mention the possibility of vertical transmission. There is no evidence of vertical transmission of ATV despite numerous attempts to detect it (J. L. Brunner \& D. M. Schock unpubl. data). However, Greer et al. (2005) found evidence of vertical transmission, or at least contamination of wood frog egg masses with a related FV3-like ranavirus. Even rare cases of vertical transmission could be important in the early dynamics of an epidemic and for the persistence of ATV and other ranaviruses.

\section{Transmission through time}

The relative importance of the different routes of transmission is uncertain, but clearly, a temporal component to ranavirus transmission must be considered in epidemiological models. Larvae are infectious soon after ATV exposure. In Expt 3, 2 of 3 larvae became infected after being held ventral surface to ventral surface with focal larvae injected with ATV just $4 \mathrm{~d}$ before (Table 2). Similarly, Focal B in Expt 4 infected one 
naïve larva just 2 d after it was exposed, and all 3 focal larvae were infectious by Day 4 (Fig. 2). It seems unlikely that these early infections were due to residual inoculum because the focal larvae were housed in clean water for at least $1 \mathrm{~d}$ before being co-housed with naïve larvae, and the volume of the water in the exposure tank was large and continually disinfected by a UV filter.

There was also a clear increase in ATV transmission from the focal larvae in Expt 4 with increasing time from initial exposure (Fig. 2). The timing of this increase, however, differed among the 3 focal larvae. Focal B, for instance, was able to infect all 10 of the naïve larvae that were exposed to it by Day 8 postinfection, while it took Focal C $16 \mathrm{~d}$ to do the same. The regression models that included both time since infection and focal larva identity (Table 3, Model 1-4) were highly supported with virtually all of the evidentiary weight $\left(\Sigma w_{i}=1\right.$; Burnham \& Anderson 2002). The vast majority of the support weight $\left(\Sigma W_{i}=0.85\right)$ was behind models that also included the size of the naïve larvae. There was little support for an interaction between focal identity and time, as opposed to simple additive effects (compare Models 3, 4 in Table 3). This suggests that the only difference among the focal larvae was the timing of the upswing in infectivity; however, only 3 focal larvae were used, so this conclusion should be interpreted cautiously. Epidemiological models on a time scale of days or weeks may need to include a function relating transmission or transmissibility to time since infection. It may be fruitful as well to link increasing infectiousness to the within-host growth of the virus population. Brunner et al. (2005) suggested that ATV kills its host when it reaches a lethal threshold number or density.

\section{Further research}

One of the most important questions is how transmission rates scale with host numbers or density. If transmission is density dependent, as would be the case if close physical contact were the dominant route of transmission, then we would expect ranavirus transmission to fade when hosts become rare. Epidemics would only be likely when host populations were large or dense. However, if most animals are infected from other sources in the environment, then host population size and density would not influence transmission rates. It seems that 2 sources of ranavirus infections should be explored. First, we need a better sense of how long ATV and other ranaviruses persist in pond water and sediment, and whether these potential environmental reservoirs contribute to new infections. More important questions involve the role of carcasses in transmission dynamics of ranaviruses: do carcasses remain infectious long enough to infect naïve animals under realistic conditions? Do naïve animals seek out infectious carcasses?

We have focused on ranavirus transmission in larval salamanders, but metamorphosed salamanders are also susceptible to infection (Jancovich et al. 1997). Previous studies showed that metamorphosed salamanders can be infected via injection, water bath, and feeding on infectious tissues (Jancovich et al. 1997, 2001). As a first approximation, it is reasonable to assume that metamorphs become infected in the same ways that larvae do, at least in aquatic environments. Transmission outside of a pond, however, is entirely unexplored. Laboratory experiments may establish possible transmission routes, but understanding transmission in nature is difficult given the cryptic and fossorial nature of many amphibians. Finally, land-use change may alter ranavirus transmission dynamics, thereby altering the impact of ranaviruses on amphibian host populations. The many small, often ephemeral marshes, springs and wetlands of North America are systematically being converted into permanent catchments and reservoirs (Semlitsch \& Bodie 1998, Tiner 2003, Pyke \& Marty 2005) or wrecked by infilling as well as drying out due to groundwater pumping. These changes in surface hydrology may increase local host population densities, consequently increasing transmission via direct contact. Changes in hydrology may also affect the persistence of ranaviruses. Ultimately, we need to know how land use changes affect hostpathogen dynamics if we are to model accurately the amphibian host and ranaviral pathogen system.

Acknowledgements. National Science Foundation (IBN9977063; DEB-0213851) grants supported this research. Animal use was conducted under Arizona State University IACUC Protocols 99-526R and 03-670R.

\section{LITERATURE CITED}

Anderson RM, May RM (1982) Coevolution of hosts and parasites. Parasitology 85:411-426

Anderson RM, May RM (1991) Infectious diseases of humans: dynamics and control. Oxford University Press, Oxford

Bollinger TK, Mao J, Schock D, Brigham RM, Chinchar VG (1999) Pathology, isolation, and preliminary molecular characterization of a novel iridovirus from tiger salamanders in Saskatchewan. J Wildl Dis 35:413-429

Brunkow PE, Collins JP (1998) Group size structure affects patterns of aggression in larval salamanders. Behav Ecol 9:508-514

Brunner JL, Richards K, Collins JP (2005) Dose and host characteristics influence virulence of ranavirus infections. Oecologia 144:399-406

Burnham KP, Anderson DR (2002) Model selection and multimodel inference: a practical information-theoretic approach. Springer, New York 
Chinchar VG (2002) Ranaviruses (Family Iridoviridae): emerging cold-blooded killers. Arch Virol 147:447-470

Collins JP, Cheek JE (1983) Effect of food and density on development of typical and cannibalistic salamander larvae in Ambystoma tigrinum nebulosum. Am Zool 23: $77-84$

Collins JP, Holomuzki JR (1984) Intraspecific variation in diet within and between trophic morphs in larval tiger salamanders (Ambystoma tigrinum nebulosum). Can J Zool 62:168-174

Collins JP, Brunner JL, Jancovich J, Schock DM (2004) A model host-pathogen system for studying infectious disease dynamics in amphibians: tiger salamanders (Ambystoma tigrinum) and Ambystoma tigrinum virus. Herpetol J 14:195-200

Daley DJ, Gani J (1999) Epidemic modelling: an introduction, Vol 15. Cambridge University Press, Cambridge

Day T (2001) Parasite transmission modes and the evolution of virulence. Evolution 55:2389-2400

de Castro F, Bolker B (2005) Mechanisms of disease-induced extinction. Ecol Lett 8:117-126

Dobson AP, Hudson P (1986) Parasites, disease and the structure of ecological communities. Trends Ecol Evol 1:11-15

Dobson AP, May RM (1986) Disease and conservation. In: Soule ME (ed) Conservation biology: the science of scarcity and diversity. Sinauer Associates, Sunderland, MA, p 345-365

Docherty DE, Meteyer CU, Wang J, Mao JH, Case ST, Chinchar VG (2003) Diagnostic and molecular evaluation of 3 iridovirus-associated salamander mortality events. J Wildl Dis 39:556-566

Dye C, Barlow ND, Begon M, Bowers RG, Bolker BM and 17 others (1995) Microparasite group report: persistence of microparasites in natural populations. In: Grenfell BT, Dobson AP (eds) Ecology of infectious diseases in natural populations. Cambridge University Press, Cambridge, p 123-143

Fijan N, Sulimanovic D, Bearzotti M, Muzinic D, Zwillenberg LO, Chilmonczyk S, Vautherot JF, Dekinkelin P (1983) Some properties of the Epithelioma Papulosum Cyprini (EPC) cell line from carp (Cyprinus carpio). Ann Inst Pasteur Vir 134:207-220

Green DE, Converse KA, Schrader AK (2002) Epizootiology of sixty-four amphibian morbidity and mortality events in the USA, 1996-2001. Ann NY Acad Sci 969:323-339

Greer AL, Berrill M, Wilson PJ (2005) Five amphibian mortality events associated with ranavirus infection in south central Ontario, Canada. Dis Aquat Org 67:9-14

Harp EM, Petranka JW (2006) Ranavirus in wood frogs (Rana sylvatica): potential sources of transmission within and between ponds. J Wildl Dis 42:307-318

Hudson PJ, Rizzoli A, Grenfell BT, Heesterbeek H, Dobson AP (eds) (2002) The ecology of wildlife diseases. Oxford University Press, New York

Institute of Laboratory Animal Resources, National Research Council (1996) Guide for the Care and Use of Laboratory Animals. National Academies Press, Washington, DC

Jancovich JK, Davidson EW, Morado JF, Jacobs BL, Collins JP (1997) Isolation of a lethal virus from the endangered tiger

Editorial responsibility: Alex Hyatt,

Geelong, Victoria, Australia salamander Ambystoma tigrinum stebbinsi. Dis Aquat Org 31:161-167

Jancovich JK, Davidson EW, Seiler A, Jacobs BL, Collins JP (2001) Transmission of the Ambystoma tigrinum virus to alternative hosts. Dis Aquat Org 46:159-163

Jancovich J, Davidson EW, Parameswaran N, Mao J, Chinchar VG, Collins JP, Jacobs BL, Storfer A (2005) Evidence for emergence of an amphibian iridoviral disease because of human-enhanced spread. Mol Ecol 14:213-224

Levin BR (1996) The evolution and maintenance of virulence in microparasites. Emerg Infect Dis 2:93-102

Lyles AM, Dobson AP (1993) Infectious disease and intensive management: population dynamics, threatened hosts, and their parasites. J Zoo Wildlife Med 24:315-326

Mao J, Tham TN, Gentry GA, Aubertin A, Chinchar VG (1996) Cloning, sequence analysis, and expression of the major capsid protein of the iridovirus frog virus 3. Virology 216:431-436

Maret TJ, Collins JP (1994) Individual responses to population size structure: the role of size variation in controlling expression of a trophic polyphenism. Oecologia 100: 279-285

Parris MJ, Davis A, Collins JP (2004) Single-host pathogen effects on mortality and behavioral responses to predators in salamanders (Urodela: Ambystomatidae). Can J Zool 82:1477-1483

Parris MJ, Storfer A, Collins JP, Davidson EW (2005) Lifehistory responses to pathogens in tiger salamander (Ambystoma tigrinum) larvae. J Herpetol 39:366-372

Pearman PB, Garner TWJ (2005) Susceptibility of Italian agile frog populations to an emerging strain of Ranavirus parallels population genetic diversity. Ecol Lett 8:401-408

Pearman PB, Garner TWJ, Straub M, Greber UF (2004) Response of the Italian agile frog (Rana latastei) to a Ranavirus, frog virus 3: a model for viral emergence in naive populations. J Wildl Dis 40:660-669

Pfennig DW, Loeb MLG, Collins JP (1991) Pathogens as a factor limiting the spread of cannibalism in tiger salamanders. Oecologia 88:161-166

Pfennig DW, Ho SG, Hoffman EA (1998) Pathogen transmission as a selective force against cannibalism. Anim Behav 55:1255-1261

Pyke CR, Marty J (2005) Cattle grazing mediates climate change impacts on ephemeral wetlands. Conserv Biol 19: 1619-1625

Semlitsch RD, Bodie JR (1998) Are small, isolated wetlands expendable? Conserv Biol 12:1129-1133

Tiner RW (2003) Estimated extent of geographically isolated wetlands in selected areas of the United States. Wetlands 23:636-652

Williams T, Barbosa-Solomieu V, Chinchar VG (2005) A decade of advances in Iridovirus research. Adv Virus Res 65:173-248

Wolf K, Bullock GL, Dunbar CE, Quimby MC (1969) Tadpole edema virus: pathogenesis and growth studies and additional sites of virus infected bullfrog tadpoles. In: Mizell M (ed) Biology of amphibian tumors. Springer Verlag, New York, p 327-336

Submitted: February 8, 2007; Accepted: June 20, 2007

Proofs received from author(s): August 29, 2007 